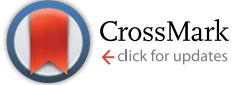

Cite this: RSC Adv., 2015, 5, 10102

Received 28th November 2014 Accepted 6th January 2015

DOI: $10.1039 / c 4 r a 15418 \mathrm{e}$

www.rsc.org/advances

\section{Microwave-promoted solventless Mizoroki-Heck reactions catalysed by Pd nanoparticles supported on laponite clay $\dagger$}

\author{
Alejandro V. Martínez, Fabio Invernizzi, Alejandro Leal-Duaso, José A. Mayoral \\ and José I. García*
}

A new family of solid catalysts has been prepared by supporting palladium nanoparticles on a synthetic clay (laponite) using a straightforward and robust procedure. These solids have been used as catalysts in a Mizoroki-Heck reaction, in solventless conditions, activated by microwave radiation. Complete conversions and high product yields can be obtained in a few minutes, and the catalyst can be efficiently recovered by extracting reaction products in essentially pure form. In the best cases, catalysts can be used up to thirteen times with good results.

\section{Introduction}

The use of microwave irradiation for promoting chemical reactions has become a versatile tool in organic synthesis. Rapid heating, reduced reaction times and, in many cases, increased yields have made microwave irradiation a commonly used tool. ${ }^{\mathbf{1 , 2}}$ In this context the use of metal catalysis in conjunction with microwaves may have significant advantages over conventional heating since the inverted temperature gradient under microwave conditions may lead to increased lifetime of the catalyst.,

There are extensive studies about Suzuki-Miyaura and, to a lesser extent, Mizoroki-Heck type $\mathrm{C}-\mathrm{C}$ cross-coupling reactions incorporating microwave irradiation using palladium complexes with different ligands, including phosphine free reactions. ${ }^{5}$ In most cases, water, ${ }^{6-11}$ DMF or aqueous mixtures of this and other organic solvents are used as reaction media. ${ }^{12-17}$ Leadbeater and co-workers showed that these reactions can be carried out with very low concentration of palladium catalysts using a phase transfer catalyst under microwaves. ${ }^{8}$ Kappe and co-workers have also used microwave activation together with very low catalyst concentrations under flow conditions. ${ }^{18}$ More recently, accelerated Heck-Mizoroki reactions have been described using ortho-palladated complexes in ionic liquids under microwaves. ${ }^{\mathbf{1 9 , 2 0}}$ Even more recently, a highly regioselective Mizoroki-Heck reaction has been described using $\mathrm{DMSO} /[\mathrm{BMIM}]\left[\mathrm{BF}_{4}\right]$ under microwave irradiation. ${ }^{21}$

Instituto de Sintesis Química y Catálisis Homogénea (ISQCH), Departamento de Química Orgánica, CSIC-Universidad de Zaragoza, Calle Pedro Cerbuna, 12, E-50009 Zaragoza, Spain.E-mail: ji.garcia@csic.es

$\dagger$ Electronic supplementary information (ESI) available. See DOI: $10.1039 / \mathrm{c} 4 \mathrm{ra} 15418 \mathrm{e}$
In contrast with the extensive literature on microwaveactivated cross-coupling reactions in homogeneous phase, the combination of this mode of activation with solid catalysts is much less abundant. Kappe and co-workers described the use of $\mathrm{Pd} / \mathrm{C},{ }^{18}$ whereas Ley and co-workers investigated the synthesis of encapsulated Pd-based catalytic systems and their use in Suzuki-Miyaura reactions. ${ }^{22} \mathrm{PdCl}_{2}$ complexes with bis(2-pyridyl)methylamine covalently bonded to an organic polymer have been described for the microwave-assisted Mizoroki-Heck, Suzuki-Miyaura and Sonogashira reactions in water, ${ }^{23}$ although the recovery of the catalysts has been only studied for the reactions carried out under conventional heating. Very recently, Suzuki-Miyaura reactions, promoted by a gold-supported palladium material, have been studied using two types of microwave activation. ${ }^{24}$ In this context, reports on the combined use of microwave activation and supported nanoparticles are even less frequent. It is worth noting the seminal work by Choudary et al., who described the use of layered double hydroxide supported palladium nanoparticles for the catalysis of several cross-coupling reactions, ${ }^{25}$ although recycling experiments were very limited. Gupton and co-workers have described the microwave-assisted synthesis of palladium nanoparticles supported on graphene, and their use in the catalysis of Suzuki-Miyaura and Mizoroki-Heck C-C crosscoupling reactions (up to 8 catalyst uses in a Suzuki coupling). ${ }^{26}$ The same group has also described the use of carbon nanotubes as support, with similar results (up to 9 uses in the same reaction). ${ }^{27}$ Graphene oxide ${ }^{28}$ and wood $^{29}$ have also been used as supports of Pd nanoparticles, but these catalytic systems display a limited recyclability. Better results have been described very recently by García-Suárez et al., who used carbonsupported Pd nanoparticles for the Suzuki-Miyaura reaction in aqueous-based media (up to 10 catalyst uses). ${ }^{30}$ Das and coworkers have described the microwave-activated Suzuki- 


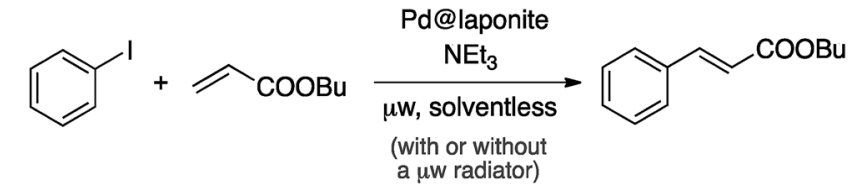

Scheme 1 Benchmark Mizoroki-Heck cross-coupling reaction used in the catalytic tests.

Miyaura reactions promoted by $\mathrm{Rh}(0)$ nano(micro)-particles supported on a modified amberlite (IRA 900), ${ }^{31}$ showing the high recyclability of the catalyst (up to 12 uses). More recently, an efficient catalyst for the microwave activated Mizoroki-Heck and Suzuki-Miyaura has been obtained by immobilization of Pd nanoparticles on a nanosilica triazine dendritic polymer, but no recycling experiments were conducted with the first reaction..$^{32}$

In general, the use of conventional heating does not lead to much better recoverability results. One of the best systems described to date, consisting of a Pd complex immobilized on the surface of Au nanoparticles, allows up to 15 uses in the Heck reaction between iodobenzene and butyl acrylate, although yields are over $90 \%$ only in the ten first reuses. ${ }^{33}$ In the case of nanoparticle-based catalysts, Pd nanoparticles supported on microporous polymers have been used up to nine times in the Suzuki reaction between bromobenzene and phenylboronic acid. ${ }^{34}$ Regarding the Mizoroki-Heck reaction, recoverability results are worse in general. Up to six catalyst uses have been described using Pd nanoparticles immobilized on different supports. ${ }^{35-37}$

It becomes apparent that, in spite of the abundant literature about microwave-assisted $\mathrm{C}-\mathrm{C}$ bond couplings, and especially of Mizoroki-Heck type, examples in which these reactions are promoted by supported nanoparticles are rather scarce, which may be due to the fact that increased mobility of the nanoparticles caused by microwaves favours their sintering, leading to a decrease of the catalytic activity and a worse recoverability. Therefore, simple strategies to use cheap and easily available supports for the preparation of supported nanoparticles to be efficiently used in microwave-assisted cross-coupling reactions are still lacking. Very recently we have described the preparation of palladium nanoparticles supported on a laponite clay and their use as catalysts in Mizoroki-Heck reactions carried out under conventional heating. ${ }^{38}$ Up to 16 catalyst uses with almost quantitative yield were possible in the best cases. In this paper we investigate if the laponite-supported palladium nanoparticles can clean and efficiently promote these kinds of reactions using low power microwave irradiation, in short reaction times and keeping good recoverability (Scheme 1).

\section{Experimental}

\subsection{General}

All reagents were purchased from commercial sources (SigmaAldrich) and used without further purification, unless otherwise indicated. Deuterated solvents were purchased from Aldrich. All analytical pure reagents were used as the only solvents in the reactions. Laponite clay was obtained from
Rockwood Additives Ltd. Microwave-promoted reactions were carried out in a CEM Discover® Microwave oven provided with a non-invasive temperature measurement by a vertically focused infrared sensor. Two different operation modes were used: constant power and automated power control based on temperature feedback (constant temperature). This oven allows continuous operating powers from 0 to $300 \mathrm{~W}$, with $1 \mathrm{~W}$ increments, and operating temperatures from $40{ }^{\circ} \mathrm{C}$ to $300^{\circ} \mathrm{C}$. Conversions and reaction yields were determined by gas chromatography using Agilent 6809A and 7890A gas chromatographs, provided with FID detectors. Compounds were characterized by NMR spectrometry on a Bruker Advance $400 \mathrm{MHz}$ spectrometer. High-resolution TEM micrographs were obtained with a JEOL-2000 FXII microscope. STEM micrographs were obtained with a FEI TECNAI F30 microscope. Field Emission SEM (FESEM) micrographs were obtained with a Carl Zeiss MERLIN $^{\mathrm{TM}}$ microscope. Thermogravimetric analyses were carried out in a SDT-2960 Simultaneous TDA-TGA.

\subsection{Preparation of palladium nanoparticles stabilized with polyvinylpyrrolidone (Pd-PVP NPs)}

This nanoparticles synthesis method is based on the reduction of a palladium(II) complex with ethanol. ${ }^{39,40}$ In a $100 \mathrm{~mL}$ flask, a $2 \mathrm{mM} \mathrm{H}_{2} \mathrm{PdCl}_{4}$ solution was prepared by mixing $35.4 \mathrm{mg}$ of $\mathrm{PdCl}_{2}$ (0.2 mmol), $2 \mathrm{~mL}$ of $0.2 \mathrm{M} \mathrm{HCl}$, and $98 \mathrm{~mL}$ of $\mathrm{H}_{2} \mathrm{O}$. A mixture of $140 \mathrm{~mL}$ of $\mathrm{H}_{2} \mathrm{O}, 94 \mathrm{~mL}$ of ethanol, $444.6 \mathrm{mg}$ of PVP and $100 \mathrm{~mL}$ of the $0.02 \mathrm{mM} \mathrm{H}_{2} \mathrm{PdCl}_{4}$ solution was refluxed in a $500 \mathrm{~mL}$ flask during $3 \mathrm{~h}$ under air to synthesize the palladium nanoparticles protected by PVP. The black solution was evaporated at reduced pressure, and the remaining black solid was dissolved in $66 \mathrm{~mL}$ of ethanol. The result was a black stable colloidal suspension of Pd-PVP NPs (3 mM) in ethanol. The size distribution was determined by analysis of the TEM images. ${ }^{38}$ The size range is $0.5-3.5$ $\mathrm{nm}$, with a typical value of $1.8 \pm 0.6 \mathrm{~nm}$.

\subsection{Preparation of laponite-supported nanoparticles}

In a $20 \mathrm{~mL}$ Schlenk flask, $1 \mathrm{~g}$ of laponite, the desired amount of ionic compound $\left(0 / 0.48 / 1.46 \mathrm{mmol}\right.$ of $[\mathrm{BMIM}]\left[\mathrm{PF}_{6}\right]$ or tetrabutylammonium bromide, TBAB), $1 \mathrm{~mL}$ of the ethanol colloidal suspension of Pd nanoparticles $(3 \mathrm{mM})$ and $6 \mathrm{~mL}$ of dichloromethane (DCM) were mixed, and the mixture magnetically stirred during $20 \mathrm{~min}$. After that, ethanol and DCM were removed under reduced pressure. The result was a powdered grey solid consisting of the Pd NPs supported onto the laponiteIL system. The size distribution was determined by analysis of the TEM images (Fig. 1). The size range observed is 1-14 $\mathrm{nm}$, with an average value of $6.3 \pm 2.8 \mathrm{~nm}$.

\subsection{General procedure for Heck coupling reactions}

In a $5 \mathrm{~mL}$ Schlenk flask, $0.3 \mathrm{mmol}$ of the corresponding aryl halide were mixed with $0.7 \mathrm{mmol}$ of the olefin and $2.2 \mathrm{mmol}$ of triethylamine. Then, the reagents mixture was transferred through a syringe to a microwavable flask containing the catalytic system previously prepared. The reaction mixture got completely adsorbed onto the solid. The reactions were carried out under microwave irradiation during a period of time 


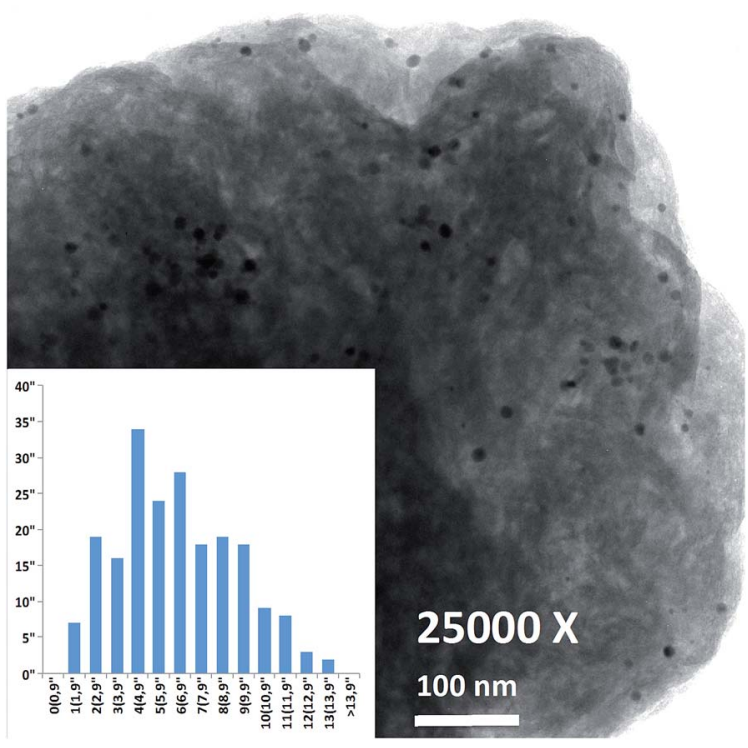

Fig. 1 Size distribution of the supported Pd nanoparticles in the fresh catalysts.

ranging from 5 to $10 \mathrm{~min}$. After finishing irradiation, the solid was transferred to a $20 \mathrm{~mL}$ Schlenk flask and extracted with hexane at $65{ }^{\circ} \mathrm{C}(1 \times 10 \mathrm{~mL}$ and then $4 \times 5 \mathrm{~mL})$. The solid was dried under reduced pressure to be reused, and the combined extracts containing the reaction products were analysed by gas chromatography. Then the solution was filtered through silica, the extraction solvent was removed under reduced pressure, and the isolated product analysed by NMR to test its purity.

${ }^{1} \mathrm{H}-\mathrm{NMR}\left(400 \mathrm{MHz}, \mathrm{CDCl}_{3}\right): 7.68(1 \mathrm{H}, \mathrm{d}, 16.0 \mathrm{~Hz}), 7.54-7.52$ $(2 \mathrm{H}, \mathrm{m}), 7.40-7.37(3 \mathrm{H}, \mathrm{m}), 6.44(1 \mathrm{H}, \mathrm{d}, 16.0 \mathrm{~Hz}), 4.22(2 \mathrm{H}, \mathrm{t}$, $6.7 \mathrm{~Hz}), 1.70(2 \mathrm{H}, \mathrm{m}), 1.44(2 \mathrm{H}, \mathrm{m}), 0.97(3 \mathrm{H}, \mathrm{t}, 7.4 \mathrm{~Hz})$.

${ }^{13} \mathrm{C}-\mathrm{NMR}\left(75 \mathrm{MHz}, \mathrm{CDCl}_{3}, \mathrm{APT}\right): 167.1\left(-, \mathrm{C}_{\text {quat }}\right), 144.5$ (+, CH), $134.5\left(-, \mathrm{C}_{\text {quat }}\right), 130.2(+, \mathrm{CH}), 128.9(+, \mathrm{CH}), 128.0$ $(+, \mathrm{CH}), 118.4(+, \mathrm{CH}), 64.4\left(-, \mathrm{CH}_{2}\right), 30.8\left(-, \mathrm{CH}_{2}\right), 19.2$ $\left(-, \mathrm{CH}_{2}\right), 13.7\left(+, \mathrm{CH}_{3}\right)$.

\section{Results and discussion}

\subsection{Preparation and characterization of the catalysts}

One of the goals of our methodology is to prepare supported nanoparticles in a straightforward manner. Thus, polyvinylpyrrolidone (PVP)-stabilized palladium nanoparticles (Pd-PVP) were prepared by reduction of $\mathrm{H}_{2} \mathrm{PdCl}_{4}$ with ethanol, following the previously established methodology. ${ }^{38-40}$ This leads to a colloidal suspension of nanoparticles with a size distribution of $1.8 \pm 0.6 \mathrm{~nm}^{38}$

Immobilization of these nanoparticles was accomplished by impregnation of the laponite clay with a dichloromethane solution of the Pd-PVP nanoparticles, either with or without an additional ionic compound (see the Experimental section for details). The SEM micrographs (Fig. 2a) show the lamellar structure of the laponite clay. TEM micrographs (Fig. 2b) clearly display the structure of the clay platelet assemblies and show the dispersion of the palladium nanoparticles on the clay surface.

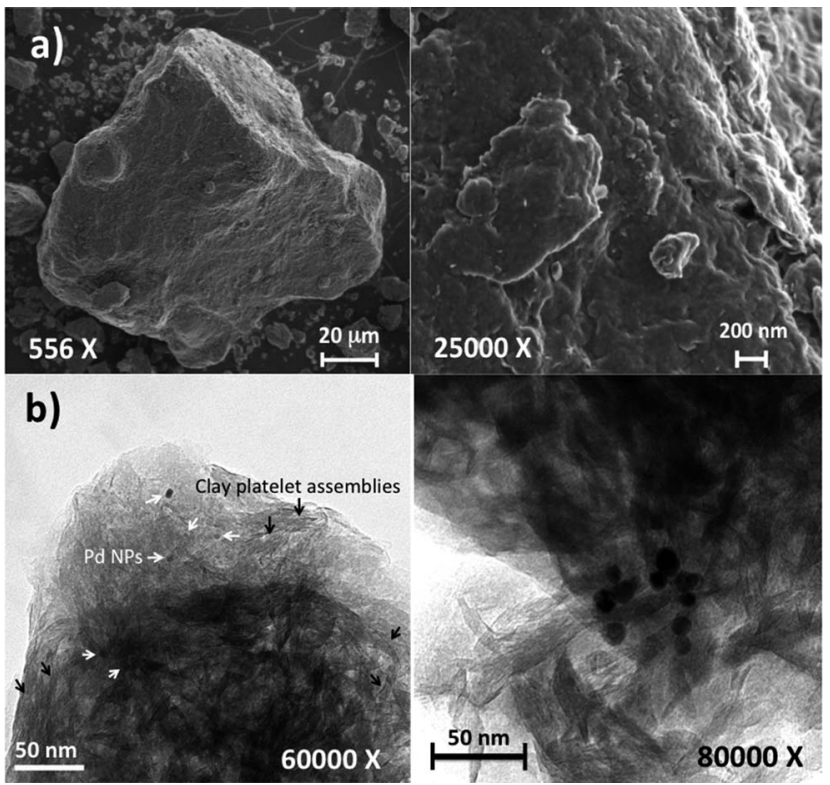

Fig. 2 (a) SEM and (b) TEM micrographs of a freshly prepared supported nanoparticles catalyst.

The size distribution of the nanoparticles was determined by analysis of the TEM images (see Experimental section).

\subsection{Catalytic tests}

The solid catalysts prepared were tested in the benchmark reaction of iodobenzene with butyl acrylate in the presence of $\mathrm{NEt}_{3}$ without the addition of any other solvent (Scheme 1). The advantages of using microwave activation in solventless conditions and in the presence of an inorganic support has been recognized for some time now. ${ }^{41-43}$ The first series of experiments were conducted at constant microwave power. The influence of microwave power and reaction time on the catalytic results was systematically studied. After each reaction the solid was thoroughly washed with hexane $(1 \times 10 \mathrm{~mL}$ and then $4 \times 5 \mathrm{~mL})$ and the organic extract analysed by gas chromatography using $n$-decane as an internal standard. The results obtained are gathered in Table 1.

As can be seen the time necessary to reach complete conversion depends on the power of the microwave source. Thus, whereas at $75 \mathrm{~W}$ complete conversion and quantitative yield is reached after only 4 minutes (entry 1 ), reaction time for the same result must be increased to 5 minutes when the reaction is irradiated at $50 \mathrm{~W}$ (entry 4). At lower powers reactions need a kind of "induction period". For instance, at $45 \mathrm{~W}$ the first reaction cycle reaches $31 \%$ yield after 5 minutes (entry 9), whereas yields around $95 \%$ are reached in the second and third cycles (entries 10 and 11). Using $25 \mathrm{~W}$ a modest $17 \%$ yield is reached after 10 minutes (entry 19), but yields over $80 \%$ are obtained in the following seven cycles (entries 20-26). It is worth noting that these reaction times represent speeding-up reaction rates by around 24 to 60 times, with regard to the best results obtained with similar catalytic systems using conventional heating. ${ }^{38}$ 
Table 1 Results obtained in the Heck reaction of iodobenzene with butyl acrylate using laponite supported $\mathrm{Pd}$ nanoparticles under microwave irradiation

\begin{tabular}{|c|c|c|c|c|}
\hline Entry & $\mu \mathrm{W}$ power $(\mathrm{W})$ & Reaction time (min) & Cycle $^{a}$ & $\%$ Yield $^{b}$ \\
\hline 1 & 75 & 4 & 1 & $>99$ \\
\hline 2 & & & 2 & 54 \\
\hline 3 & & & 3 & 24 \\
\hline 4 & 50 & 5 & 1 & $>99$ \\
\hline 5 & & & 2 & 93 \\
\hline 6 & & & 3 & 94 \\
\hline 7 & & & 4 & 60 \\
\hline 8 & & & 5 & 22 \\
\hline 9 & 45 & 5 & 1 & 31 \\
\hline 10 & & & 2 & 94 \\
\hline 11 & & & 3 & 97 \\
\hline 12 & & & 4 & 72 \\
\hline 13 & 40 & 5 & 1 & 45 \\
\hline 14 & & & 2 & 62 \\
\hline 15 & & & 3 & 87 \\
\hline 16 & & & 4 & 92 \\
\hline 17 & & & 5 & 94 \\
\hline 18 & & & 6 & 60 \\
\hline 19 & 25 & 10 & 1 & 17 \\
\hline 20 & & & 2 & 93 \\
\hline 21 & & & 3 & 95 \\
\hline 22 & & & 4 & 93 \\
\hline 23 & & & 5 & 88 \\
\hline 24 & & & 6 & 84 \\
\hline 25 & & & 7 & 81 \\
\hline 26 & & & 8 & 82 \\
\hline 27 & & & 9 & 61 \\
\hline 28 & & & 10 & 69 \\
\hline 29 & & & 11 & 76 \\
\hline 30 & & & 12 & 10 \\
\hline 31 & 50 & 5 & 1 & 87 \\
\hline 32 & 25 & 5 & 2 & 60 \\
\hline 33 & & & 3 & 69 \\
\hline 34 & & & 4 & 76 \\
\hline 35 & & & 5 & 88 \\
\hline 36 & & & 6 & 43 \\
\hline
\end{tabular}

${ }^{a}$ Full results are available in the ESI. ${ }^{b}$ Determined by gas chromatography. Regio- and stereoselectivity to butyl (E)-cinnamate were $100 \%$ in all cases.

It is also clear that catalyst recovery is better when reactions are carried out under low power irradiation, and so in reactions carried out at $75 \mathrm{~W}$ yield decreases below $80 \%$ in the first reuse, whereas this result is observed after five reaction cycles at $40 \mathrm{~W}$ and after eight cycles when reactions are carried out at $25 \mathrm{~W}$. Trying to avoid the induction period and to improve catalyst recovery, we carried out the reaction under microwaves at $50 \mathrm{~W}$ in the first cycle and at $25 \mathrm{~W}$ in the successive reuses (entries 31-36). Although in the first cycle ca. 90\% conversion was reached after 5 minutes, the recovery of the catalyst was in fact worse than that observed with the catalyst used at $25 \mathrm{~W}$ in all reactions (entries 19-30). As the catalyst is reused in further cycles, full extraction of reaction products becomes more difficult because of the accumulation of the concomitant triethylammonium iodide. This results in erratic yield values, as in the case of entries 26-29 in Table 1. The yield increase observed in some cycles may be due to incomplete product extraction in the precedent cycles, a situation that is common with a low polar solvent is used to extract products from a heterogeneous catalyst. $^{\mathbf{4 4}}$

The particle size of the clay support largely decreases upon catalyst reuse. This seems to be due to extensive delamination of the clay structure in reaction conditions, as shown by the SEM micrographs of the exhaust catalyst (Fig. 3). As can be seen, the platelets are more clearly revealed than in the case of the freshly prepared catalyst (Fig. 2a), indicating the partial delamination of the structure.

Deactivation of the catalyst may be due to palladium leaching, so we compared ICP-MS Pd analyses of the fresh catalyst and two used catalysts, namely that used in 6 reaction cycles at $40 \mathrm{~W}$ during $5 \mathrm{~min}$, which still keeps a noticeably activity, and the catalyst used 12 times at $25 \mathrm{~W}$ during $10 \mathrm{~min}$, which is almost exhaust. In order to avoid any interference in the analyses by the presence of organic materials, catalysts were calcined under air at $550{ }^{\circ} \mathrm{C}$ for $8 \mathrm{~h}$ before being submitted to analysis. Furthermore, palladium content variations were determined by using $\mathrm{Pd} / \mathrm{Mg}$ molar ratios, given that $\mathrm{Mg}$ content in the clay should not be modified under the reaction conditions. We had already proven the adequacy of this protocol in a previous work. ${ }^{38}$ The measured $\mathrm{Pd} / \mathrm{Mg}$ ratio decreases from $4.55 \times 10^{-4}$ in the fresh catalyst to $3.75 \times 10^{-4}$ in that used 6 times and $2.43 \times 10^{-4}$ in the exhaust one after 12 uses, which represent $17.6 \%$ and $46.5 \%$ Pd leaching, respectively. The latter leaching value is not high enough to justify almost complete deactivation, since in previous studies, we have observed significant activity (more than $40 \%$ yield), even after $90 \% \mathrm{Pd}$ leaching. ${ }^{38}$ In this context, it should be mentioned that there is still an open discussion about the nature of the true catalytic species involved in the catalysis of cross-coupling reactions by Pd nanoparticles. There is some evidence supporting the formation either of coordinatively unsaturated Pd atoms or anionic halide complexes, which would be the true catalytic species, and that would redeposit onto the support at the end of the reaction. ${ }^{45}$ The formation of these species would also explain the leaching of palladium from the catalyst, as well as the decrease of the size of the Pd nanoparticles by loss of palladium atoms. In our case, since the nanoparticles are deposited onto a solid support and the reaction is carried out in solventless conditions (even though the reagents are liquids, after adsorption onto the catalyst, the whole system has the

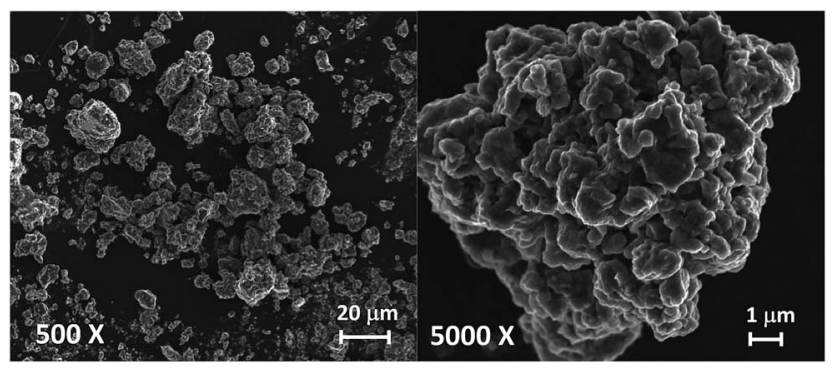

Fig. 3 SEM micrographs of a used catalyst. 
appearance of a dry powder), it is difficult to ascertain the true nature of the catalytic species. In a previous work, hot extraction experiments did not revealed the presence of catalytically active soluble species. ${ }^{38}$

A second possibility for catalyst deactivation is the sintering of the Pd-nanoparticles due to the high local temperatures generated by the microwave heating. Scanning transmission electron micrographs (STEM) show the presence of big size palladium nanoparticles in the catalyst used 6 times (Fig. 4), but they also reveal the presence of a large number of small nanoparticles, which are still able to catalyse the reactions. Unfortunately, STEM micrographs in the case of the exhaust catalyst did not allow localizing any Pd nanoparticle, in spite of keeping more than half of the initial Pd content, which could also be due to the abovementioned Pd dissolution-redeposition process.

Finally, it can be thought that catalyst may be poisoned either by the concomitant by-product, the ammonium salt that remains over the anionic support, or by some by-products coming from it, given that this ionic by-product efficiently absorbs microwaves and, in fact, less active catalysts become dark brown-coloured. TGA analyses indicate that exhausted catalyst loses around $45 \%$ of their mass at $356{ }^{\circ} \mathrm{C}$ (see ESI $\dagger$ ), and elemental $\mathrm{C}, \mathrm{H}$ and $\mathrm{N}$ analysis reveals that the proportions of these elements match those of the ammonium salt. Electronprobe X-ray fluorescence (EP-XRF) analysis in SEM samples reveals the presence of iodine, supporting the massive presence of ammonium salt in the used catalyst. This fact would also account for the more efficient recovery of the catalyst in the reactions carried out under low power microwave irradiation. It may be thought that the observed "induction period" is only an artifact and that the increase in yields after the first cycle is due to the more efficient absorption of the microwaves in the presence of the ammonium salt formed. In fact, in the reaction carried out under microwaves at $25 \mathrm{~W}$ during $10 \mathrm{~min}$, the measured reaction temperatures increase from $90{ }^{\circ} \mathrm{C}$ to $125^{\circ} \mathrm{C}$ after six cycles and reach $180^{\circ} \mathrm{C}$ in the last use of the catalyst, when it is already deactivated. It should be mentioned that reactants and products are practically transparent to microwave

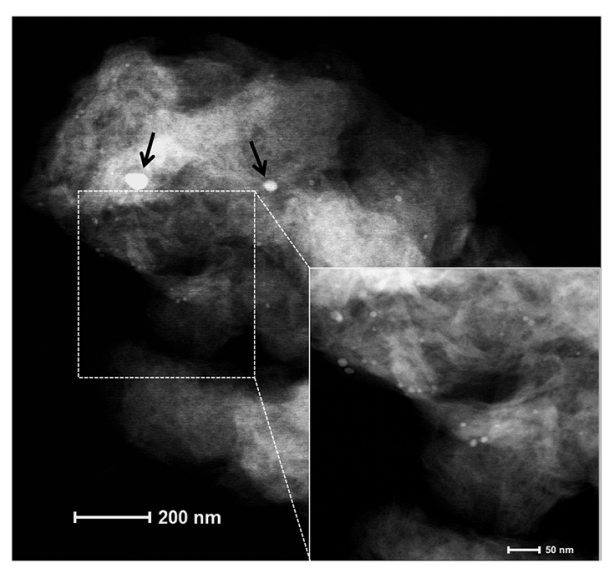

Fig. 4 STEM micrograph of the catalyst used in six reaction cycles at $40 \mathrm{~W}$ during $5 \mathrm{~min}$, showing large Pd nanoparticles (black arrows), together with smaller ones. radiation, the ammonium salt and (to a lesser extent) the support being the only responsible for the heating, due to their better absorption of the microwave radiation through the wellknown ionic conduction and dielectric heating mechanisms., ${ }^{2,3}$

Trying to avoid catalyst poisoning by decomposition products of the ammonium salt at high temperatures, we carried out the reaction at $25 \mathrm{~W}$, the power leading to the best results in the previous experiments, keeping the temperature of the reaction constant (Table 2).

An "induction period" is again observed in the reaction carried out at $80{ }^{\circ} \mathrm{C}$, this effect being less important above this temperature. On the other hand, the catalyst recovery deteriorates with the reaction temperature increases, being clearly worse at $110{ }^{\circ} \mathrm{C}$. Catalyst stability does not improve with regard to the experiments carried out at constant microwaves power. The catalyst can be used during six cycles with good results, but the yield decreases in the following cycles. Even more important, there is an increasing amount of by-products detected in the GC analyses, which results in a noticeable decrease of the

Table 2 Results obtained in the Heck reaction of iodobenzene with butyl acrylate using laponite supported $\mathrm{Pd}$ nanoparticles under microwave irradiation $(25 \mathrm{~W})$ at constant temperature

\begin{tabular}{|c|c|c|c|}
\hline Entry & $T\left({ }^{\circ} \mathrm{C}\right)$ & Cycle $^{a}$ & Yield $^{b, c}(\%)$ \\
\hline 1 & 80 & 1 & 39 \\
\hline 2 & & 2 & 95 \\
\hline 3 & & 3 & 96 \\
\hline 4 & & 4 & 95 \\
\hline 5 & & 5 & 93 \\
\hline 6 & & 6 & 98 \\
\hline 7 & & 7 & 77 \\
\hline 8 & & 8 & 77 \\
\hline 9 & 90 & 1 & 90 \\
\hline 10 & & 2 & 94 \\
\hline 11 & & 3 & 98 \\
\hline 12 & & 4 & 97 \\
\hline 13 & & 5 & 97 \\
\hline 14 & & 6 & 98 \\
\hline 15 & & 7 & 71 \\
\hline 16 & & 8 & 69 \\
\hline 17 & 100 & 1 & 78 \\
\hline 18 & & 2 & 97 \\
\hline 19 & & 3 & 97 \\
\hline 20 & & 4 & 97 \\
\hline 21 & & 5 & 97 \\
\hline 22 & & 6 & 98 \\
\hline 23 & & 7 & 74 \\
\hline 24 & & 8 & 61 \\
\hline 25 & 110 & 1 & 87 \\
\hline 26 & & 2 & 97 \\
\hline 27 & & 3 & 97 \\
\hline 28 & & 4 & 97 \\
\hline 29 & & 5 & 98 \\
\hline 30 & & 6 & 74 \\
\hline 31 & & 7 & 29 \\
\hline
\end{tabular}

${ }^{a}$ All reactions were carried out in 10 minutes on a $0.9 \mathrm{mmol}$ scale of iodobenzene, 1.41 equiv. of butyl acrylate and $2.15 \mathrm{mmol}^{\circ} \mathrm{NEt}_{3}$ in solventless conditions. ${ }^{b}$ Determined by GC. Regio- and stereoselectivity to $n$-butyl (E)-cinnamate were $100 \%$ in all cases. ${ }^{c}$ Full results are available in the ESI. 
isolated product yield (more than $30 \%$ with regard to the yields determined by GC; see Table S2 in the ESI $\dagger$ ). As catalyst poisoning does not seem to be avoided by the constant temperature system of the microwave oven used, we continued our study using microwaves activation at a constant power.

As previously mentioned, the formation of the ammonium salt concomitant product in the first cycles favours the absorption of microwaves energy by the system in the subsequent uses, which explains the lower yields often observed in the first catalyst use. With this hypothesis in mind, we decided to incorporate an ionic compound as part of catalysts preparation to improve the absorption of microwaves energy from the first reaction cycle. In a first series of experiments we used $0.3 \mathrm{~mL}$ of [BMIM] $\left[\mathrm{PF}_{6}\right](1.46 \mathrm{mmol})$ per gram of laponite, because this is the amount of ionic liquid that behaves as a solid on the laponite surface, as demonstrated by solid-state NMR experiments. ${ }^{46}$ The results of these catalytic tests are gathered in Table 3.

Table 3 Results obtained in the Heck reaction of iodobenzene with butyl acrylate using laponite supported $\mathrm{Pd}$ nanoparticles under

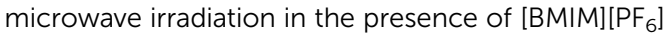

\begin{tabular}{|c|c|c|c|c|c|}
\hline Entry & $\begin{array}{l}{[\mathrm{BMIM}]\left[\mathrm{PF}_{6}\right]} \\
\left(\mathrm{mmol} \mathrm{g}^{-1} \text { clay }\right)\end{array}$ & $\begin{array}{l}\mu \mathrm{W} \text { power } \\
(\mathrm{W})\end{array}$ & $\begin{array}{l}\text { Reaction time } \\
\text { (min) }\end{array}$ & Cycle $^{a}$ & $\%$ Yield $^{b}$ \\
\hline 1 & 0.3 & 30 & 5 & 1 & 80 \\
\hline 2 & & & & 2 & 33 \\
\hline 3 & & 25 & 5 & 1 & 92 \\
\hline 4 & & & & 2 & 23 \\
\hline 5 & & 15 & 10 & 1 & 77 \\
\hline 6 & & & & 3 & 78 \\
\hline 7 & & & & 6 & 91 \\
\hline 8 & & & & 12 & 87 \\
\hline 9 & & & & 13 & 81 \\
\hline 10 & & & & 14 & 23 \\
\hline 11 & 0.1 & 45 & 5 & 1 & 91 \\
\hline 12 & & & & 2 & 90 \\
\hline 13 & & & & 3 & 89 \\
\hline 14 & & & & 4 & 10 \\
\hline 15 & & 40 & 5 & 1 & 84 \\
\hline 16 & & & & 2 & 91 \\
\hline 17 & & & & 3 & 87 \\
\hline 18 & & & & 4 & 89 \\
\hline 19 & & & & 5 & 81 \\
\hline 20 & & & & 6 & n.d. \\
\hline 21 & & 35 & 5 & 1 & 45 \\
\hline 22 & & & & 2 & 74 \\
\hline 23 & & & & 3 & 97 \\
\hline 24 & & & & 4 & 90 \\
\hline 25 & & & & 5 & 6 \\
\hline 26 & & 20 & 10 & 1 & 69 \\
\hline 27 & & & & 2 & 97 \\
\hline 28 & & & & 3 & 89 \\
\hline 29 & & & & 7 & 90 \\
\hline 30 & & & & 8 & 83 \\
\hline 31 & & & & 11 & 65 \\
\hline 32 & & & & 12 & 42 \\
\hline 33 & & & & 14 & 8 \\
\hline
\end{tabular}

${ }^{a}$ Full results are available in the ESI. ${ }^{b}$ Determined by gas chromatography. Regio- and stereoselectivity to $n$-butyl $(E)$-cinnamate were $100 \%$ in all cases.
As can be seen high yields are obtained in only 5 minutes under microwave powers as low as 25 and $30 \mathrm{~W}$ (entries 1-4), however the catalyst cannot be reused and it gets deactivated after the first cycle. Using $15 \mathrm{~W}$ and 10 minutes of reaction, 77\% yield is obtained in the first cycle, which subsequently increases to about $90 \%$ in the following cycles and the catalyst can be used up to 13 times with the similar yields (entries 5-10). Pd leaching, as determined after 14 uses, is $c a .43 \%$, a value slightly lower than that previously discussed, above all if we take into consideration that this catalyst has been used in two more cycles than the previous one. We tried to improve catalyst recovery by reducing the amount of ionic liquid to only $0.1 \mathrm{~mL}$ ( $0.48 \mathrm{mmol})$ per gram of support, but in this case higher irradiation power is necessary to reach high yields. Furthermore, although the "induction period" is not observed for reactions carried out over $35 \mathrm{~W}$, it is again evident for lower microwaves powers. In no case catalyst recovery is significantly improved. Concerning catalyst deactivation and Pd leaching, the latter is ca. $48 \%$ in the case of the catalyst used 13 times at $20 \mathrm{~W}$ (entries 26-33), again similar to the previous values. On the other hand, for the catalyst used six times at $40 \mathrm{~W}$ and that is completely deactivated, Pd leaching is as low as 7.5\%. This

Table 4 Results obtained in the Heck reaction of iodobenzene with butyl acrylate using laponite supported Pd nanoparticles under microwave irradiation in the presence of tetrabutylammonium bromide (TBAB)

\begin{tabular}{|c|c|c|c|c|c|}
\hline Entry & $\begin{array}{l}\text { TBAB } \\
\left(\mathrm{mmol} \mathrm{g}^{-1} \text { clay }\right)\end{array}$ & $\begin{array}{l}\mu \mathrm{W} \text { power } \\
(\mathrm{W})\end{array}$ & $t(\min )$ & Cycle $^{a}$ & Yield $^{b}(\%)$ \\
\hline 1 & 1.46 & 25 & 5 & 1 & $>99$ \\
\hline 2 & & & & 2 & 98 \\
\hline 3 & & & & 3 & 98 \\
\hline 4 & & & & 8 & 60 \\
\hline 5 & & & & 9 & 40 \\
\hline 6 & & & & 10 & 6 \\
\hline 7 & & 15 & 10 & 1 & $>99$ \\
\hline 8 & & & & 2 & $>99$ \\
\hline 9 & & & & 3 & 83 \\
\hline 10 & & & & 4 & 45 \\
\hline 11 & & 20 & 5 & 1 & 92 \\
\hline 12 & & & & 2 & 19 \\
\hline 13 & & & & 4 & 36 \\
\hline 14 & 0.48 & 40 & 5 & 1 & 89 \\
\hline 15 & & & & 2 & 92 \\
\hline 16 & & & & 3 & 92 \\
\hline 17 & & & & 4 & 96 \\
\hline 18 & & & & 5 & 69 \\
\hline 19 & & & & 6 & 30 \\
\hline 20 & & 20 & 10 & 1 & 66 \\
\hline 21 & & & & 2 & 95 \\
\hline 22 & & & & 3 & 86 \\
\hline 23 & & & & 4 & 54 \\
\hline 24 & & & & 5 & 54 \\
\hline 25 & & & & 6 & 35 \\
\hline 26 & & 40 & 5 & 1 & 91 \\
\hline 27 & & 20 & 5 & 2 & 61 \\
\hline
\end{tabular}

${ }^{a}$ Full results are available in the ESI. ${ }^{b}$ Determined by gas chromatography. Regio- and stereoselectivity to $n$-butyl $(E)$-cinnamate were $100 \%$ in all cases. 
constitutes the clearest example showing that leaching is not the main responsible for catalyst deactivation.

Given that the concomitant by-product is an ammonium salt we also explored the $a b$ initio activation of the reaction by the addition of tetrabutylammonium bromide (TBAB). As in the case of the ionic liquid, the same two different molar amounts were used in the preparation of the fresh catalyst. The results obtained with these series of catalysts are gathered in Table 4.

The addition of this ammonium salt allows reaching excellent yields in short reaction times and with very low power of the microwave irradiation. However, in general, catalysts get deactivated faster than in the case of using the imidazolium salt in the same or similar reaction conditions. These results point towards the same conclusion, i.e., the ammonium salt allows a more efficient adsorption of microwaves, but it decomposes faster, poisoning the catalyst. As in the precedent case, Pd leaching $\left(27.4 \%\right.$ in the reactions at $25 \mathrm{~W}$ with $1.46 \mathrm{mmol} \mathrm{g}^{-1}$ of TBAB and $35 \%$ in the reactions at $40 \mathrm{~W}$ with $0.48 \mathrm{mmol} \mathrm{g}^{-1}$ of TBAB) is not high enough to account for the dramatic catalyst deactivation observed.

\section{Conclusions}

We have prepared a number of stable solid catalysts by supporting palladium nanoparticles onto laponite, a synthetic clay, using a straightforward and robust procedure. These solids have been used as catalysts in a Mizoroki-Heck reaction, in solventless conditions, activated by microwave radiation. Complete conversions and high product yields can be obtained in a few minutes, which represents a noteworthy speed-up of the reaction with regard to conventional heating. The catalysts can be efficiently recovered by extracting reaction products with an auxiliary solvent. The concomitant by-product, tetraethylammonium iodide, remains deposited on the laponite upon extraction, so the reaction product is obtained from the extract in almost pure form, and contamination by salt is avoided. Furthermore, the ammonium salt acts as a microwave radiator through an ionic conduction mechanism, so the effectiveness of the reaction activation increases in subsequent uses of the catalyst. The same effect can also be obtained by including an ionic compound at the beginning, during the preparation of the fresh catalysts.

Concerning catalyst recovery and reuse, the use of high microwave power is detrimental for catalyst life, probably because of the decomposition of the ammonium salt, and subsequent catalyst poisoning by coke deposition. As a consequence, the best performances upon catalyst recovery are obtained using microwave power not higher than $25 \mathrm{~W}$, in the case of catalysts prepared without any external microwave radiator, and $15 \mathrm{~W}$, in the case of catalysts prepared with addition of an ionic compound. In both cases, between 10 and 13 catalyst recoveries and reuses can be conducted with total conversion and high isolated yields, which match the current state of the art for this reaction, outperforming most of the examples described so far using supported Pd nanoparticles. However, it is not clear that microwave activation may become the activation method of choice for solventless reactions using this kind of catalyst, unless the problem of decomposition of the accumulated ammonium salt can be overcome. Work on this subject is currently underway.

\section{Acknowledgements}

Financial support from the Spanish MINECO (project CTQ201128124-C02-01), the European Social Fund (ESF) and the Gobierno de Aragón (Grupo Consolidado E11) is gratefully acknowledged. We also thank Ma Angeles Laguna and Ana C. Gallego, from the Service of Electron Microscopy of Materials of the University of Zaragoza for their valuable assistance in the TEM and FESEM experiments and to Dr Alfonso Cornejo and Dr Víctor Martínez-Merino, from UPNA, for their valuable advise and collaboration.

\section{References}

1 A. de la Hoz and A. Loupy, Microwaves in Organic Synthesis, Wiley-VCH Verlag GmbH, Weinheim, 2012.

2 C. O. Kappe, D. Dallinger and S. S. Murphree, Practical Microwave Synthesis for Organic Chemists - Strategies, Instruments, and Protocols, Wiley-VCH Verlag GmbH, 2009.

3 C. O. Kappe, Angew. Chem., Int. Ed., 2004, 43, 6250-6284.

4 M. Larhed, C. Moberg and A. Hallberg, Acc. Chem. Res., 2002, 35, 717-727.

5 P. Appukkuttan and E. Van der Eycken, Eur. J. Org. Chem., 2008, 2008, 1133-1155.

6 N. E. Leadbeater and M. Marco, Org. Lett., 2002, 4, 29732976.

7 R. K. Arvela and N. E. Leadbeater, Org. Lett., 2005, 7, 21012104.

8 R. K. Arvela and N. E. Leadbeater, J. Org. Chem., 2005, 70, 1786-1790.

9 F. Chanthavong and N. E. Leadbeater, Tetrahedron Lett., 2006, 47, 1909-1912.

10 K. M. Dawood, Tetrahedron, 2007, 63, 9642-9651.

11 B. Allam and K. Singh, Synthesis, 2011, 2011, 1125-1131.

12 H. Prokopcová, J. Ramírez, E. Fernández and C. O. Kappe, Tetrahedron Lett., 2008, 49, 4831-4835.

13 Ü. Yılmaz, N. Şireci, S. Deniz and H. Küçükbay, Appl. Organomet. Chem., 2010, 24, 414-420.

14 H. Küçükbay, N. Şireci, Ü. Yılmaz, M. Akkurt, Ş. P. Yalçın, M. Nawaz Tahir and H. Ott, Appl. Organomet. Chem., 2011, 25, 255-261.

15 Y. Zhang, Z. Lv, H. Zhong, M. Zhang, T. Zhang, W. Zhang and K. Li, Tetrahedron, 2012, 68, 9777-9787.

16 Ü. Yılmaz, H. Küçükbay, S. Deniz and N. Şireci, Molecules, 2013, 18, 2501-2517.

17 Ü. Yılmaz, S. Deniz, H. Küçükbay and N. Şireci, Molecules, 2013, 18, 3712-3724.

18 T. N. Glasnov, S. Findenig and C. O. Kappe, Chem.-Eur. J., 2009, 15, 1001-1010.

19 A. R. Hajipour and F. Rafiee, Appl. Organomet. Chem., 2011, 25, 542-551.

20 A. R. Hajipour and F. Rafiee, Appl. Organomet. Chem., 2013, 27, 412-418. 
21 Z. Zhou, T. Xie, Q. Hu, J. Xue and J. Shi, ARKIVOC, 2012, 164172.

22 I. R. Baxendale, C. M. Griffiths-Jones, S. V. Ley and G. K. Tranmer, Chem.-Eur. J., 2006, 12, 4407-4416.

23 J. Gil-Moltó, S. Karlström and C. Nájera, Tetrahedron, 2005, 61, 12168-12176.

24 M. Al-Amin, M. Akimoto, T. Tameno, Y. Ohki, N. Takahashi, N. Hoshiya, S. Shuto and M. Arisawa, Green Chem., 2013, 15, 1142-1145.

25 B. M. Choudary, S. Madhi, N. S. Chowdari, M. L. Kantam and B. Sreedhar, J. Am. Chem. Soc., 2002, 124, 14127-14136.

26 A. R. Siamaki, A. E. R. S. Khder, V. Abdelsayed, M. S. El-Shall and B. F. Gupton, J. Catal., 2011, 279, 1-11.

27 A. R. Siamaki, Y. Lin, K. Woodberry, J. W. Connell and B. F. Gupton, J. Mater. Chem. A, 2013, 1, 12909-12918.

28 S. Moussa, A. R. Siamaki, B. F. Gupton and M. S. El-Shall, ACS Catal., 2012, 2, 145-154.

29 F. Heinrich, M. T. Keßler, S. Dohmen, M. Singh, M. H. G. Prechtl and S. Mathur, Eur. J. Inorg. Chem., 2012, 2012, 6027-6033.

30 E. J. García-Suárez, P. Lara, A. B. García, M. Ojeda, R. Luque and K. Philippot, Appl. Catal., A, 2013, 468, 59-67.

31 N. R. Guha, C. B. Reddy, N. Aggarwal, D. Sharma, A. K. Shil, Bandna and P. Das, Adv. Synth. Catal., 2012, 354, 2911-2915.

32 A. L. Isfahani, I. Mohammadpoor-Baltork, V. Mirkhani, A. R. Khosropour, M. Moghadam, S. Tangestaninejad and R. Kia, Adv. Synth. Catal., 2013, 355, 957-972.
33 J.-N. Young, T.-C. Chang, S.-C. Tsai, L. Yang and S. J. Yu, J. Catal., 2010, 272, 253-261.

34 S. Ogasawara and S. Kato, J. Am. Chem. Soc., 2010, 132, 46084613.

35 Z. Zhang and Z. Wang, J. Org. Chem., 2006, 71, 7485-7487.

36 A. Khazaei, S. Rahmati, Z. Hekmatian and S. Saeednia, J. Mol. Catal. A: Chem., 2013, 372, 160-166.

37 H. Firouzabadi, N. Iranpoor, A. Ghaderi, M. Gholinejad, S. Rahimi and S. Jokar, RSC Adv., 2014, 4, 27674-27682.

38 A. V. Martínez, J. A. Mayoral and J. I. García, Appl. Catal., A, 2014, 472, 21-28.

39 T. Teranishi and M. Miyake, Chem. Mater., 1998, 10, 594600.

40 Y. Li, E. Boone and M. A. El-Sayed, Langmuir, 2002, 18, 49214925.

41 R. S. Varma, Green Chem., 1999, 1, 43-55.

42 H. Cho, F. Török and B. Török, Green Chem., 2014, 16, 36233634.

43 R. S. Varma, Tetrahedron, 2002, 58, 1235-1255.

44 J. I. García, C. I. Herrerías, J. A. Mayoral, A. C. Miñana and C. Sáenz, Eur. J. Org. Chem., 2014, 1531-1540.

45 K. Köhler, W. Kleist and S. S. Pröckl, Inorg. Chem., 2007, 46, 1876-1883.

46 M. Rosa Castillo, J. M. Fraile and J. A. Mayoral, Langmuir, 2012, 28, 11364-11375. 